\title{
Prevalence of migraine in low-tension glaucoma and primary open-angle glaucoma in Japanese
}

\author{
Tomoaki Usui, Kazuo Iwata, Motohiro Shirakashi, Haruki Abe
}

\begin{abstract}
We studied the prevalence of migraine in lowtension glaucoma (LTG) and primary openangle glaucoma (POAG). Seventy seven Japanese patients with LTG, 73 with POAG, and 75 normal subjects were randomly selected and tested with a headache questionnaire. The prevalence of headache with or without typical migrainous features (unilateral headache or ocular pain, nausea, vomiting, and visual disturbance before headache) was $51 \%$ in LTG, $42 \%$ in POAG, and $44 \%$ in normal patients. The prevalence of headache with two migrainous features or more (probable migraine) was $17 \%$ in LTG, $11 \%$ in POAG, and $12 \%$ in normal subjects. The prevalence of headache with three migrainous features (classical migraine) was $5 \%$ in LTG, $3 \%$ in POAG, and $3 \%$ in normal subjects. There was no statistically significant difference in the prevalence of any types of migraine between the three groups of patients $(p>0.05)$. These results suggest there is no significant relationship between migraine and LTG or POAG in Japanese patients.
\end{abstract}

Low-tension glaucoma (LTG) is characterised by glaucomatous optic disc cupping and visual field loss in eyes that have consistently normal intraocular pressures, open angles, and the absence of any contributing ocular or systemic disorders. The clinical features of LTG resemble those of primary open-angle glaucoma (POAG) except for the absence of increased intraocular pressure.

The pathogenesis of LTG is still uncertain. Several investigators have reported that LTG and POAG have different aetiologies, ${ }^{1}$ and others have reported that LTG is a variant of POAG. ${ }^{2}$ Recently Phelps $e t a l^{34}$ studied the prevalence of migraine in patients with LTG, POAG, ocular hypertension, and normal subjects using a headache questionnaire, and reported a significant relationship between migraine and LTG: a higher prevalence of migraine in patients with LTG than in other groups of patients. Drances and Ederer ${ }^{6}$ found their data convincing. In the present study, using the identical headache questionnaire as used by Phelps and Corbett, ${ }^{3}$ we studied the prevalence of migraine in normal subjects and in Japanese patients with LTG and POAG.

\section{Patients and methods}

We gave the headache questionnaire to 91 randomly selected Japanese patients with LTG, 92 with POAG, and 99 normal subjects. The patients had all been diagnosed and followed up in our clinic. Patients with LTG had glaucomatous optic disc cupping and visual field defects in at least one eye, and the intraocular pressures (IOPs) remained lower than $21 \mathrm{mmHg}$ on repeated measurements; they had no history of retrobulbar neuritis, anterior ischaemic optic neuropathy, or intracranial lesion. Patients with POAG had glaucomatous optic disc cupping and visual field defects, and an IOP of $21 \mathrm{mmHg}$ or more. Normal subjects, who were selected from patients in our clinic, had no abnormal ocular findings except refractive error in both eyes.

To compare the prevalence of migraine in Japanese patients with LTG and POAG with the results of Phelps and Corbett, ${ }^{3}$ the same questionnaire as Phelps and Corbett used was applied in the present study. Nearly all the subjects filled out the questionnaire by themselves in the waiting room in our clinic, but to some it was sent by mail because of difficulty in visiting. The questionnaire was filled up by $85 \%$ of patients with LTG, $79 \%$ of patients with POAG, and $76 \%$ of normal subjects (response rate). Informed consent was obtained from each subject after explanation of the purpose of the study. A headache which had three migrainous features (unilateral headache or ocular pain; nausea, vomiting; visual disturbance before headache) was defined as 'classical migraine'; a headache which had two migrainous features or more as 'probable migraine'; and a headache which had only one migrainous feature or more as 'possible migraine'. Student's $t$ test and the $\chi^{2}$ test were used for the statistical analysis, and the statistically significant level was taken as $\mathbf{p}<0.05$.

\section{Results}

The questionnaire was completed by a total of 225 subjects, including 77 patients with LTG, 73 patients with POAG, and 75 normal subjects. The mean age of the subjects was $58 \cdot 2$ (SD 13.7) years, and the male to female ratio was 108:117. The prevalence of headache in each of these three groups is summarised in Table 1 , and the distribution of age and sex in each group is shown in Table 2. The mean age of each of the three groups showed no statistically significant difference $(\mathrm{p}>0.05)$. The distributions by sex in the three groups were identical. The prevalence of headache with or without migrainous features (headache overall) was $51 \%(39 / 77)$ in patients with LTG, $42 \%(31 / 73)$ in patients with POAG, and $44 \%(33 / 75)$ in normal subjects, respectively. Classical migraine which had three migrainous features was observed in four of the 77 patients with LTG $(5 \%)$, in two of the 73 patients with POAG (3\%), and in two of the 75 normal subjects (3\%). There was no statistically significant difference between these three groups 
( $p>0.05)$. Probable migraine which had two migrainous features or more was observed in 13 of the 77 patients with LTG $(17 \%)$, in eight of the 73 patients with POAG (11\%), and in nine of the 75 normal subjects $(12 \%)$. Although the prevalence of probable migraine was highest in the patients with LTG, no statistically difference was observed between the three groups $(p>0.05)$. And there was no significant difference in the prevalence of possible migraine or headache overall between the groups $(\mathrm{p}>0.05)$.

Table 3 shows the prevalence of headache with regard to age and sex. The prevalence of headache in patients with LTG was somewhat higher than those in other subjects of either sex. However, no statistically significant difference in the prevalence of headache was found between the three groups ( $p>0.05)$.

Following the questionnaire we reviewed the four patients with LTG who had a history of classical migraine. We found that two of them had misunderstood the questionnaire, for one patient had confused scintillating scotoma with photopsia or myodesopsia and the other had nausea or vomiting unrelated to headache. In only two of four patients with LTG was classical migraine strongly suspected. We also reviewed the two patients with POAG and two normal subjects who had three migrainous features; one normal subject had misunderstood the questionnaire.

\section{Discussion}

Migraine is characterised by recurrent, periodic headaches which are commonly unilateral and are usually associated with visual prodromata, nausea, vomiting, and other focal neurological symptoms, including numbness and tingling of the lips, face, and hands, slight confusion of thinking, weakness of an arm or leg, mild aphasia, dizziness, and uncertainty of gait, or drowsiness. ${ }^{7}$ The visual symptoms are probably related to ischaemia in the occipital cortex. ${ }^{8}$ The prevalence of migraine is reported to be approximately $10 \%$ of the population. ${ }^{9}$

Corbett et $a l^{4}$ found that 12 of 27 patients (44\%) with LTG had a history of common or classical migraine. According to their case control study, which included the administration of a headache questionnaire, ${ }^{3}$ a higher prevalence of headache with or without features of migraine was found in patients with LTG than in patients with POAG, ocular hypertension, and normal controls. They therefore considered there were close aetiological and therapeutic connections between LTG and migraine.

Our results are shown to compare with those of Phelps and Corbett in Tables 4, 5, and 6. In our Japanese patients with LTG, POAG, and normal subjects the prevalence of headache with or without migrainous features (headache overall) and headache with two migrainous features or more (probable migraine) were lower than those in Phelps and Corbett's series (Tables 4 and 5). On the other hand the prevalence of cases with three migrainous features (classical migraine) was almost the same in our study and theirs (Table 6). Although in Phelps and Corbett's series, there was a statistically significant dif-
Table 1 Prevalence of headache (total)

\begin{tabular}{lllll}
\hline & $\begin{array}{l}\text { Classical } \\
\text { migraine }\end{array}$ & $\begin{array}{l}\text { Probable } \\
\text { migraine }\end{array}$ & $\begin{array}{l}\text { Possible } \\
\text { migraine }\end{array}$ & $\begin{array}{c}\text { Headache } \\
\text { overall }\end{array}$ \\
\hline LTG & 4 & 13 & 28 & 39 \\
$(\mathbf{n}=77)$ & $(5 \%)$ & $(17 \%)$ & $(36 \%)$ & $(51 \%)$ \\
POAG & 2 & 8 & 23 & 31 \\
$(\mathbf{n}=73)$ & $(3 \%)$ & $(11 \%)$ & $(32 \%)$ & $(42 \%)$ \\
Normal & 2 & 9 & 20 & 33 \\
$(\mathbf{n}=75)$ & $(3 \%)$ & $(12 \%)$ & $(27 \%)$ & $(44 \%)$ \\
\hline
\end{tabular}

Table 2 Distribution by age and sex

\begin{tabular}{llll}
\hline Age & LTG (male:female) & POAG & Normal \\
\hline $30-39$ & $9(5: 4)$ & $10(6: 4)$ & $11(4: 7)$ \\
$40-49$ & $10(4: 6)$ & $10(6: 4)$ & $12(6: 6)$ \\
$50-59$ & $18(8: 10)$ & $16(8: 8)$ & $14(6: 8)$ \\
$60-69$ & $20(10: 10)$ & $19(9: 10)$ & $20(10: 10)$ \\
$70-79$ & $20(10: 10)$ & $18(8: 10)$ & $18(8: 10)$ \\
Total & $77(37: 40)$ & $73(37: 36)$ & $75(34: 41)$ \\
\hline Mean & $58 \cdot 7($ SD 13.4) & $58 \cdot 3($ SD 13.5) & $57 \cdot 6($ SD 14.2) \\
\hline
\end{tabular}

Table 3 Prevalence of headache

\begin{tabular}{cccccccc}
\hline & \multicolumn{3}{c}{ Male } & \multicolumn{5}{l}{ Female } \\
\cline { 2 - 3 } \cline { 6 - 8 } Age & LTG & POAG & Normal & & LTG & POAG & Normal \\
\hline $30-39$ & $3 / 5$ & $4 / 6$ & $1 / 4$ & & $3 / 4$ & $2 / 4$ & $5 / 7$ \\
$40-49$ & $2 / 4$ & $2 / 6$ & $3 / 6$ & & $4 / 6$ & $3 / 4$ & $4 / 6$ \\
$50-59$ & $3 / 8$ & $4 / 8$ & $3 / 6$ & & $5 / 10$ & $4 / 8$ & $4 / 8$ \\
$60-69$ & $4 / 10$ & $2 / 9$ & $3 / 10$ & & $6 / 10$ & $3 / 10$ & $4 / 10$ \\
$70-79$ & $5 / 10$ & $3 / 8$ & $2 / 8$ & & $4 / 10$ & $4 / 10$ & $4 / 10$ \\
Total & $17 / 37$ & $15 / 37$ & $12 / 34$ & & $22 / 40$ & $16 / 36$ & $21 / 41$ \\
& $(46 \%)$ & $(41 \%)$ & $(35 \%)$ & & $(55 \%)$ & $(44 \%)$ & $(51 \%)$ \\
\hline
\end{tabular}

Table 4 Prevalence of headache overall

\begin{tabular}{lll}
\hline & Ourclinic & Phelps and Corbett \\
\hline LTG & $39 / 77$ & $47 / 54$ \\
& $(51 \%)$ & $(87 \%)$ \\
POAG & $31 / 73$ & $124 / 182$ \\
& $(42 \%)$ & $(68 \%)$ \\
Normal & $33 / 75$ & $396 / 493$ \\
& $(44 \%)$ & $(80 \%)$ \\
\hline
\end{tabular}

Table 5 Prevalence of probable migraine

\begin{tabular}{lll}
\hline & Ourclinic & Phelps and Corbett \\
\hline LTG & $13 / 77$ & $16 / 54$ \\
& $(17 \%)$ & $(30 \%)$ \\
POAG & $8 / 73$ & $33 / 182$ \\
& $(11 \%)$ & $(18 \%)$ \\
Normal & $9 / 75$ & $96 / 493$ \\
& $(12 \%)$ & $(19 \%)$ \\
\hline
\end{tabular}

Table 6 Prevalence of classical migraine

\begin{tabular}{lll}
\hline & Our clinic & Phelps and Corbett \\
\hline LTG & $4 / 77$ & $4 / 54$ \\
& $(5 \%)$ & $(7 \%)$ \\
POAG & $2 / 73$ & $10 / 182$ \\
& $(3 \%)$ & $(5 \%)$ \\
Normal & $2 / 75$ & $14 / 493$ \\
& $(3 \%)$ & $(3 \%)$ \\
\hline
\end{tabular}

ference between LTG and POAG in the prevalence of headache overall, in our series of Japanese patients there was no such difference between the three groups of patients (Tables 4, 5 , and 6).

There are several possible reasons for the differences in prevalence of headache between our series and that of Phelps and Corbett, including racial differences and differences in the distribution by age and sex. Although a questionnaire seems to be a relatively objective method of determining prevalence of headache, the results may be influenced by whether each 
patient could understand the questions clearly. In fact a thorough review of the patients suspected of classical migraine from their responses to the questionnaire revealed that only two had classical migraine. Thus its prevalence in LTG was found to be very low, $3 \%(2 / 77)$.

Our study did not show any significant relationship between migraine and LTG or POAG, and suggested that the patient's angiospastic state may have no implications for optic nerve damage in either LTG or POAG.

1 Chumbley LC, Brubaker RF. Low-tension glaucoma. Am f Ophthalmol 1976; 81: 761-7.
2 Drance SM, Sweeney VP, Morgan RW, Feldman F. Studies of factors involved in the production of low tension glaucoma. factors involved in the production

3 Phelps CD, Corbett JJ. Migraine and low-tension glaucoma: a case-control study. Invest Ophthalmol Vis Sci 1985; 26: $1105-8$.

4 Corbett JJ, Phelps CD, Eslinger P, Montague PR. The neurologic evaluation of patients with low-tension glaucoma Invest Ophthalmol Vis Sci 1985; 26: 1101-5.

5 Drance SM. The neurologic evaluation of patients with lowtension glaucoma, comment. Surv Ophthalmol 1986; 31: 74-5.

6 Ederer F. Migraine and low-tension glaucoma. Invest Ophthalmol Vis Sci 1986; 27: 632-3.

7 Adams RD, Victor $M$. Headache and other craniofacial pains. Principles of neurology. 4th ed. New York: McGraw-Hill,

8 Ziegler DK, Friedman AP. Migraine. Merritt's textbook of neurology. 8th ed. Philadelphia, London: Lea and Febiger, chapter 20, 1989: 773 .

9 Troost BD. Migraine. Clinical ophthalmology. Philadelphia: Harper and Row, 1983; 2: chapter 19. 